\title{
Interactions of metals and Apolipoprotein E in Alzheimer's disease
}

\author{
He Xu, David I. Finkelstein and Paul A. Adlard* \\ The Florey Institute of Neuroscience and Mental Health, The University of Melbourne, Melbourne, VIC, Australia
}

Edited by:

Roger S. Chung, Macquarie

University, Australia

Reviewed by:

Marta Barrachina, Bellvitge

Biomedical Research Institute (IDIBELL), Spain

Roger S. Chung, Macquarie

University, Australia

*Correspondence:

Paul A. Adlard, The Florey Institute of Neuroscience and Mental Health, The University of Melbourne, 30

Royal Parade, Parkville, 3052,

Melbourne, VIC, Australia

e-mail:paul.adlard@florey.edu.au

\begin{abstract}
Alzheimer's disease (AD) is the most common form of dementia, which is characterized by the neuropathological accumulation of extracellular amyloid plaques and intracellular neurofibrillary tangles (NFTs). Clinically, patients will endure a gradual erosion of memory and other higher order cognitive functions. Whilst the underlying etiology of the disease remains to be definitively identified, a body of work has developed over the last two decades demonstrating that $A D$ plasma/serum and brain are characterized by a dyshomeostasis in a number of metal ions. Furthermore, these metals (such as zinc, copper and iron) play roles in the regulation of the levels of AD-related proteins, including the amyloid precursor protein (APP) and tau. It is becoming apparent that metals also interact with other proteins, including apolipoprotein $E$ (ApoE). The Apolipoprotein $E$ gene (APOE) is critically associated with $A D$, with APOE4 representing the strongest genetic risk factor for the development of late-onset $A D$. In this review we will summarize the evidence supporting a role for metals in the function of ApoE and its consequent role in the pathogenesis of AD.
\end{abstract}

Keywords: Apolipoprotein E, Alzheimer's disease, zinc, copper, metals

\section{INTRODUCTION}

Apolipoprotein E (ApoE) is the predominant apolipoprotein in the brain where it is synthesized and secreted primarily by astrocytes in high-density lipoprotein (HDL)-like particle (Bu, 2009). A primary function of ApoE is to serve as a ligand for the low-density lipoprotein (LDL) receptor family of proteins, which mediate delivery of cholesterol to neurons. That function is essential for axonal growth, synaptic formation and remodeling and all of those events are important for learning, memory formation and neuronal repair (Mauch et al., 2001; Pfrieger, 2003). Decreases in the levels of ApoE or LDL receptors lead to synaptic remodeling impairment and a progressive loss of synapses in the cortex and hippocampus (Mulder et al., 2004; Liu et al., 2010).

ApoE is also a polymorphic protein with three common allele variants: APOE2, APOE3 and APOE4. The APOE4 gene is the strongest and only confirmed genetic risk factor for the development of late onset Alzheimer's disease (LOAD), which enhances the risk level by three times in heterozygous individuals and by twelve times in homozygous individuals (Bertram, 2009). The least frequent APOE2 allele (found in $5-10 \%$ of individuals) seems to have a protective effect against the development of $\mathrm{AD}$ while the most frequent APOE3 allele (found in $70-80 \%$ of the population) represents intermediate risk (Corder et al., 1994; Mahley and Huang, 2006). The structural differences between the three ApoE isoforms is limited to amino acid residues 112 and 158, where either cysteine or arginine is present: ApoE2 (Cys112, Cys158), ApoE3 (Cys112, Arg158) and ApoE4 (Arg112, Arg158; Mahley and Rall, 2000). The single amino acid difference at these two positions affects the structure of ApoE isoforms and their ability to bind lipids, receptors and amyloid beta $(A \beta)$, the latter which is the main constituent of the extracellular plaques found in the AD brain (Zhong and Weisgraber, 2009; Chen et al., 2011; Frieden and Garai, 2012).

The connection between metals, $\mathrm{A} \beta$ and abnormal forms of tau (as found in the neurofibrillary tangles (NFT) present in the $\mathrm{AD}$ brain) has been investigated extensively in the pathogenesis of AD (Grasso et al., 2012; Greenough et al., 2013; Wärmländer et al., 2013). However, the effects of metallation on ApoE are less well known. In this review, evidence supporting the hypothesis that zinc and copper play a role in the function of ApoE will be covered, along with the key points on the current understanding of the influence of ApoE and metals on the pathogenesis of $\mathrm{AD}$.

\section{APOE AND ITS ROLE IN AD PATHOGENESIS}

APOE4 has been found to be associated with an increased prevalence of $\mathrm{AD}$ and a lower age of onset. Clinical data shows the frequency of $\mathrm{AD}$ and mean onset age are $91 \%$ and 68 years old in APOE 4 homozygous carriers, $47 \%$ and 76 years old in APOE4 heterozygous carriers, and 20\% and 84 years old in APOE4 noncarriers (Corder et al., 1993; Rebeck et al., 1993); suggesting that APOE4 genotype confers a significantly higher risk of development of $\mathrm{AD}$ with an earlier age of onset in a gene dose-dependent manner. It has also been reported that the prevalence of an E4 allele is considerably higher in mild cognitive impairment (MCI) than in control individuals ( $\mathrm{Pa}$ et al., 2009); with APOE4 $\mathrm{MCI}$ individuals showing poorer memory performance at an 
earlier stage in $\mathrm{AD}$ compared with non-carriers (Smith et al., 1998). APOE4 can also influence cognition in healthy people. Healthy APOE4 carriers show an accelerated longitudinal decline in memory tests (Caselli et al., 2004, 2007). In the brain, ApoE mediates delivery of cholesterol to neurons, which is essential for axonal growth, synaptic formation and remodeling and all of those events are important for learning, memory formation and neuronal repair (Mauch et al., 2001; Pfrieger, 2003). Astrocytes preferentially degrade ApoE4, leading to reduced ApoE4 secretion and ultimately to reduced brain ApoE levels (Riddell et al., 2008). Taken together therefore, the lack of functional ApoE present in $\mathrm{AD}$ is likely to directly contribute to the cognitive impairment seen in this disease.

One of the first pieces of evidence linking ApoE to $\mathrm{AD}$ pathology was the observation of ApoE immunoreactivity in extracellular amyloid plaques and NFTs (Namba et al., 1991). It has since been shown that ApoE forms complexes with $A \beta$ and these complexes are thought to influence $A \beta$ deposition and clearance (Wildsmith et al., 2013). A $\beta$ deposition detected by Pittsburgh Compound B positron emission tomography (PIBPET) follows a strong APOE allele-dependent pattern $(\mathrm{E} 4>\mathrm{E} 3$ $>$ E2) (Kok et al., 2009; Morris et al., 2010; Castellano et al., 2011). An ApoE isoform-specific effect on the amount of $A \beta$ accumulation as well as in the number of amyloid plaques was also found in amyloid precursor protein (APP) transgenic mice expressing different human ApoE isoforms (E4 > E3 > E2; Fagan et al., 2000, 2002; Fryer et al., 2005b). The mechanisms underlying isoform-specific influences on $A \beta$ aggregation and accumulation in the brains are not fully understood, but it's likely due to their different abilities to clear $A \beta$ (Wildsmith et al., 2013). In vitro and in vivo studies show that many ApoE receptors are involved in ApoE-mediated $\mathrm{A} \beta$ clearance from the brain (Bu, 2009; Kim et al., 2009; Holtzman et al., 2012). A recent study demonstrated that ApoE loses its ability to clear $A \beta$ when ApoE is cleaved at the hinge region of ApoE (Jones et al., 2011). After cleavage, the ApoE-A $\beta$ complex cannot bind to ApoE receptors due to the lack of N-terminal ApoE which contains the binding sites of ApoE receptors. It also has been demonstrated that ApoE4 is more susceptible to the cleavage at hinge region (Jones et al., 2011), increasing the likelihood of the ApoE receptor binding region (N-terminal ApoE) being cleaved, which supports the idea that ApoE4 has the least ability to clear $A \beta$ compared to ApoE2 and ApoE3. Another supportive finding is that ApoE4 clears $A \beta$ at blood brain barrier (BBB) via the very low-density lipoprotein receptor (VLDLR) whereas $A \beta$ is cleared at a higher rate in the presence of ApoE2 and ApoE3 by both VLDLR and lipoprotein related protein 1 (LRP1; Deane and Zlokovic, 2007).

It has also been proposed that the poor stability, clearance and poor lipidation status of ApoE4 accounts for its contribution to an elevated risk for the development of $\mathrm{AD}$. ApoE4 is the least stable of all three ApoE isoforms (Morrow et al., 2002) and has been reported to be preferentially susceptible to proteolytic degradation into cytotoxic fragments (Huang et al., 2001). Much higher levels of ApoE fragments are detected in the brains of $\mathrm{AD}$ patients (Huang et al., 2001; Harris et al., 2003; Jones et al., 2011) and these fragments have been shown to damage hippocampal neurons and result in memory impairment (Harris et al., 2003; Andrews-Zwilling et al., 2010).

ApoE4 is a less effective lipid carrier under physiological conditions than ApoE3 or ApoE2 (Michikawa et al., 2000; Hara et al., 2003). Lipidation of ApoE is mediated primarily by ATP-binding cassette A1 (ABCA1) and the lipidation status of ApoE is related to its $\mathrm{A} \beta$-binding properties (Tokuda et al., 2000). Reducing ApoE lipidation status by ablating ABCA1 in APP transgenic mice markedly enhances brain amyloid plaque levels, and conversely, enhancing ApoE lipidation status by the up-regulation of ABCA1 significantly reduced amyloid load (Kim et al., 2009). These results are consistent with the hypothesis that non-lipidated ApoE in the brain can stimulate $A \beta$ aggregation and deposition (Hatters et al., 2006) while lipidated ApoE facilitates the clearance of $A \beta$ and it is much less susceptible to proteolysis than lipid-free ApoE (Weisgraber et al., 1994; Narayanaswami et al., 2004). Some ApoE receptors and ABCA1 appear to influence ApoE expression and lipidation (Hirsch-Reinshagen et al., 2004; Wahrle et al., 2004; Fryer et al., 2005a; Liu et al., 2007; Wahrle et al., 2008).

Based on the pathological definition of the disease, $\mathrm{AD}$ is associated not only with the abnormal accumulation of amyloid plaques, but also with the accumulation of NFTs which form intracellularly and are composed primarily of aggregated phosphorylated and acetylated tau (Iqbal et al., 2010). Tau primarily stabilizes microtubules, and its aggregation in $\mathrm{AD}$ causes deficits through a loss-of-function mechanism. Recently, evidence has also shown that when it is abnormally modified, tau becomes enriched in dendritic spines where it can interfere with neurotransmission (Morris et al., 2011). Evidence from in vivo and in vitro studies indicates that ApoE3 and ApoE4 function differently with respect to the phosphorylation and aggregation of tau. ApoE3 binds to the microtubule-binding repeat regions of tau with its N-terminal domain (Strittmatter et al., 1994), however, this interaction can be impeded by the phosphorylation of tau. On the other hand, whilst ApoE4 has been shown to not significantly interact with tau (Strittmatter et al., 1994), it does increase tau phosphorylation and accumulation in the neuronal soma and dendrites, facilitating the formation of NFTs during aging and AD progression (Harris et al., 2003; Brecht et al., 2004; AndrewsZwilling et al., 2010). One proposed mechanism is that ApoE4 can activate the extracellular signal-regulated kinases (ERK) pathway in $\mathrm{AD}$ brains and lead to tau phosphorylation, which is likely modulated by zinc (Harris et al., 2004).

\section{THE INVOLVEMENT OF METALS IN AD PATHOGENESIS}

The formation of the classical neuropathological features of $\mathrm{AD}$ are not only influenced by APOE genotype, but also mediated or triggered by an imbalance of metal ions. Altered metal homeostasis has been demonstrated in the brain and plasma/serum in $\mathrm{AD}$ patients. Compared with age-matched control, AD patients show elevated zinc and copper in cerebrospinal fluid (CSF; Hozumi et al., 2011), whereas plasma and serum zinc was found to be lower (Vural et al., 2010). Free copper in the blood of AD patients is substantially higher than controls (Squitti et al., 2014). In addition, the concentration of zinc, copper, and iron in brain parenchyma (350 $\mu \mathrm{M}, 70 \mu \mathrm{M}$, and $340 \mu \mathrm{M}$, respectively) are further elevated in $\mathrm{AD}$ patients $(800 \mu \mathrm{M}, 300 \mu \mathrm{M}$, and $700 \mu \mathrm{M}$, 
respectively; Lovell et al., 1998). These metals are also enriched in both senile plaques and NFTs (Ayton et al., 2013). Zinc, along with copper and iron (released during neural transmission), directly bind to $A \beta$ and accelerate its aggregation and accumulation into amyloid plaques (Morante, 2008; Altamura and Muckenthaler, 2009). Therefore, the zinc, copper and iron sequestration into amyloid deposits is thought to result in a loss of cellular and synaptic metals. The loss of synaptic zinc is particularly relevant to the maintenance of normal cognition. An important regulator of synaptic zinc is the zinc transporter-3 ( $\mathrm{ZnT} 3$ ) protein which is essential for loading zinc into synaptic vesicles (Linkous et al., 2008). It has been shown that ZnT3 levels decrease with aging in the brains of both mice and humans and are reduced even further in the brains of AD patients (Adlard et al., 2010). ZnT3 $\mathrm{KO}$ mice display defects in learning and memory at 6 months of age, and the authors suggest that these mice provide a phenocopy for the synaptic and memory deficits of AD (Adlard et al., 2010). In addition, copper is another important metal involved in the cognitive decline in AD. Free copper in blood is potentially toxic, particularly if the free copper pool expands, as it does in Wilson's disease (Brewer et al., 1998). More importantly, there's a strong positive correlation between the level of free copper and the severity of cognitive loss in AD (Squitti et al., 2006), which can be observed over a given period of time (Squitti et al., 2009).

Although we still do not know if the metal ion dyshomeostasis present in $\mathrm{AD}$ is a cause or consequence of the disease, there is a growing body of evidence showing a direct correlation between metal ions and key $\mathrm{AD}$-related key proteins. Both zinc and copper facilitate $A \beta$ aggregation. $A \beta$ tends to form fibrils in the presence of zinc, whereas in the presence of copper it prefers to form oligomers (Tõugu et al., 2009). The copper-A $\beta$ oligomer complex has been shown to be more toxic than the zinc $A \beta$ fibrils, which in some conditions actually confer protection (Rosenblum, 2014). Metal dyshomeostasis is also involved in the regulation of other $\mathrm{AD}$-related proteins, like APP and tau. Zinc, for example, regulates the activity of some of the secretases involved in the processing and function of APP, with $\alpha$-secretase activity up-regulated by zinc indirectly through a disintegrin and metalloproteinase (ADAM; Lammich et al., 1999); however, the activity of the $\gamma$-secretase complex is inhibited by zinc (Hoke et al., 2005). The copper binding domain of APP (histidine residues 149 and 151) is crucial for APP stability and metabolism (Spoerri et al., 2012) and copper enhances APP dimerization and promotes A $\beta$ production (Noda et al., 2013). Consistent with this concept, APP knockout mice have elevated copper levels in the cerebral corte (White et al., 1999). These studies show that APP may directly influence copper homeostasis, and its interactions with copper may be also neurotoxic.

Metals are also involved in tau pathology, and are enriched in tangle-bearing neurons (Sayre et al., 2000). Synaptically released zinc induces tau hyper-phosphorylation through pathways including Src-dependent, glycogen synthase kinase $3 \beta$ (GSK3 $\beta$ ) and ERK pathways (Lei et al., 2011; Xiong et al., 2013). Copper directly binds to tau (Martic et al., 2013) and regulates its aggregation and phosphorylation (Squitti et al., 2006; Zhou et al., 2007). Aberrant activation of cyclin-dependent kinase 5 (CDK5) was found to be correlated with the tau pathology after chronic copper exposure in a mouse model of AD (Kitazawa et al., 2009). Iron binding to the hyper-phosphorylated tau protein also facilitates the formation of the NFTs (Altamura and Muckenthaler, 2009) and the iron chelator, deferoxamine (DFO), decreases ironinduced activities of CDK5 and GSK3 $\beta$ and tau phosphorylation (Guo et al., 2013). Thus, the development of the two most prominent pathological features of the $\mathrm{AD}$ brain, plaques and tangles, are likely to be mediated by metal ions. This area has been extensively reviewed in the past (Adlard and Bush, 2006; Bush and Tanzi, 2008; Duce and Bush, 2010; Hung et al., 2010; Ayton et al., 2013), and supports the notion of the regulation of metal homeostasis as a promising area of investigation for future $\mathrm{AD}$ therapeutics.

\section{EVIDENCE SUPPORTING THE LINK BETWEEN METALS AND ApoE}

The mechanism by which ApoE4 is associated with AD is still unknown; however, an emerging linkage between metals and ApoE might give a clue. Evidence shows that ApoE isoforms bind to metals such as zinc, copper and iron (that are also involved in the pathogenesis of $\mathrm{AD}$ ), with the affinity for copper being greater than for iron and zinc (Miyata and Smith, 1996). The precise binding sites for metals on ApoE have yet to be determined, but the four-helix bundle of the N-terminus may allow a coordination of metals (Miyata and Smith, 1996). The metal sequestration properties of ApoE might present metals to $\mathrm{A} \beta$ peptides, leading to amyloid deposition or it might account for the antioxidant function of ApoE in $\mathrm{AD}$ development. Furthermore, studies support the notion that ApoE2 has the highest affinity for zinc and ApoE4 has the lowest. This is likely a result of structural differences amongst the three isoforms. Cysteine is a strong ligand for zinc, arginine is not (Karlin and Zhu, 1997), so the affinity for zinc is predicted to be greatest for ApoE2 which has cysteine residues at amino acid position 112 and 158 and weakest for ApoE4 which lacks cysteine residues. This likelihood is supported by the results showing that ApoE protects $A \beta$ from zinc-induced precipitation in the order of ApoE2 > ApoE3 > ApoE4 (Moir et al., 1999). It is also speculated that ApoE4 has a reduced copper binding capacity because of its lack of cysteine residues (Hung et al., 2013). Although direct evidence for the metal:ApoE interaction needs to be demonstrated, these data clearly provide a potentially important avenue of investigation for understanding the mechanism underlying the higher risk of $\mathrm{AD}$ in APOE4 carriers. Metal ions, such as zinc, play an essential role in stabilizing protein structures and contributing to protein function (Wang et al., 2010). We further speculate that metal binding might help to stabilize ApoE in an order of E2 $>$ E3 > E4 in the proteolytic process, which leads to less ApoE4 and more ApoE4 fragments. This is consistent with the previous findings that APOE4 carriers have less full-length ApoE but more ApoE fragments in brain parenchyma and plasma than APOE2 carriers (Riddell et al., 2008; Gupta et al., 2011); with decreased ApoE levels in APOE4 carriers considered an important factor for $\mathrm{AD}$ onset/development (Verghese et al., 2011; Holtzman et al., 2012). Therefore, the stability of ApoE may be affected by metals, and this may help account for the 
differential effect of the three ApoE alleles on the development of AD.

There are also a number of studies that have investigated the effect of metals on the expression levels of apolipoproteins. The gene expression of apolipoprotein $\mathrm{A}$ and apolipoprotein $\mathrm{B}$ has been found to be regulated by zinc and copper (Zhang et al., 1995; Reaves et al., 2000; Cui et al., 2002) and more importantly, another AD-related apolipoprotein, clusterin (apolipoprotein J; Jones, 2010), is increased after zinc exposure (Trougakos et al., 2006). It is possible that altered metal levels in $\mathrm{AD}$ patients might affect the expression/transportation of apolipoproteins, including
ApoE. Alternatively, metals might have different effects on the expression/transportation of the three ApoE isoforms, accounting for the different risk levels for $\mathrm{AD}$ among the three allele carriers.

Finally, studies have shown that ApoE can regulate synaptic zinc and glutamate levels in the hippocampus. The depletion of ApoE leads to a reduced expression of $\mathrm{ZnT} 3$, in parallel with a reduction in synaptic zinc content in APOE knockout mice, suggesting the ApoE modulates zinc homeostasis in the brain (Lee et al., 2010). The synaptic zinc is required for long-time potentiation (LTP) and is critical for the proper functioning of

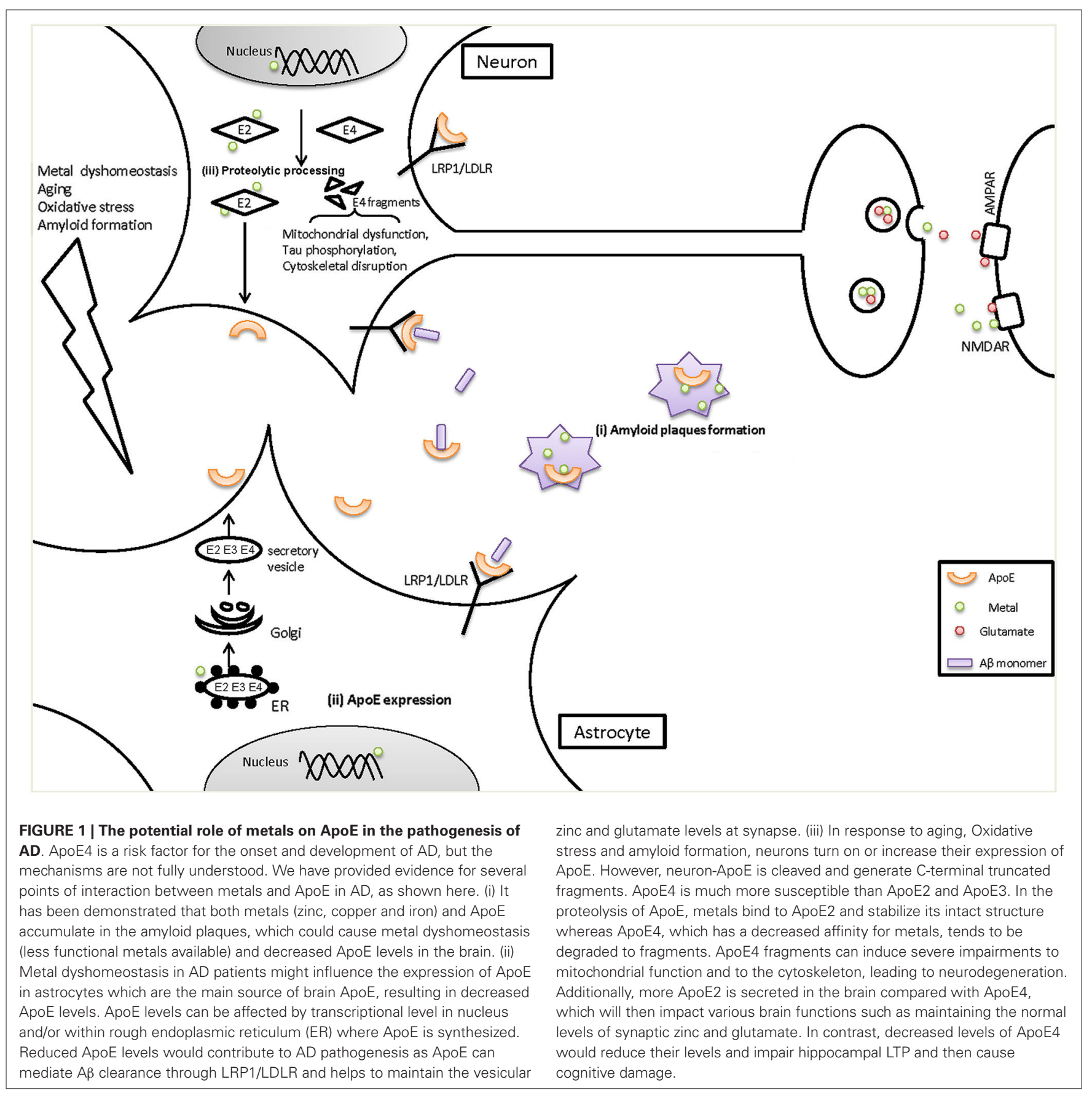


hippocampal circuitry in health and disease (Pan et al., 2011). So decreased ApoE levels would lead to synaptic zinc deficiency and cognitive impairments. Studies with human APOE Targeted Replacement (TR) mice demonstrated that compared to APOE2 and APOE3 TR mice, APOE4 TR mice have decreased levels of glutamate (Dumanis et al., 2013), which is an excitatory neurotransmitter co-released with zinc at the synapse during neuronal activity, and which is important to maintain normal hippocampal LTP and cognitive function (Paoletti et al., 2009). Thus, this may contribute to the increased risk of neurodegeneration associated with APOE4 carriers.

Taken together, these findings support an interaction between metals and ApoE that may be important in the pathogenesis of $\mathrm{AD}$ (Figure 1). In this review we summarized the evidence showing that metals bind to ApoE in an isoform-specific way, and that ApoE modulates metal homeostasis in the brain. There is also the possibility that metals may regulate ApoE levels. However, some key issues need to be directly addressed to provide definitive evidence for a metal:ApoE interaction, including the following: (1) Do metals (apart from zinc) have differential affinities for the three ApoE isoforms?; (2) Is the stability or degradation of ApoE isoforms affected by metal binding?; (3) Are changes in neuron- and astrocyte-specific ApoE expression/transportation caused by altered metal levels in $\mathrm{AD}$ ? If so, what's the underlying mechanism? Thus, further study is required for an integrated understanding of the interactions between metals and ApoE, and how they act together in the development and progression of $\mathrm{AD}$.

\section{ACKNOWLEDGMENTS}

Paul A. Adlard and David I. Finkelstein are supported by the NHMRC and ARC. In addition, the Florey Institute of Neuroscience and Mental Health acknowledge the strong support from the Victorian Government and in particular the funding from the Operational Infrastructure Support Grant.

\section{REFERENCES}

Adlard, P. A., and Bush, A. I. (2006). Metals and Alzheimer's disease. J. Alzheimers Dis. 10, 145-163.

Adlard, P. A., Parncutt, J. M., Finkelstein, D. I., and Bush, A. I. (2010). Cognitive loss in zinc transporter-3 knock-out mice: a phenocopy for the synaptic and memory deficits of Alzheimer's disease? J. Neurosci. 30, 1631-1636. doi: 10. 1523/jneurosci.5255-09.2010

Altamura, S., and Muckenthaler, M. U. (2009). Iron toxicity in diseases of aging: Alzheimer's disease, Parkinson's disease and atherosclerosis. J. Alzheimers Dis. 16, 879-895. doi: 10.3233/JAD-2009-1010

Andrews-Zwilling, Y., Bien-Ly, N., Xu, Q., Li, G., Bernardo, A., Yoon, S. Y., et al. (2010). Apolipoprotein E4 causes age- and Tau-dependent impairment of GABAergic interneurons, leading to learning and memory deficits in mice. J. Neurosci. 30, 13707-13717. doi: 10.1523/jneurosci.4040-10.2010

Ayton, S., Lei, P., and Bush, A. I. (2013). Metallostasis in Alzheimer's disease. Free Radic. Biol. Med. 62, 76-89. doi: 10.1016/j.freeradbiomed.2012.10.558

Bertram, L. (2009). Alzheimer's disease genetics current status and future perspectives. Int. Rev. Neurobiol. 84, 167-184. doi: 10.1016/S0074-7742(09) 00409-7

Brecht, W. J., Harris, F. M., Chang, S., Tesseur, I., Yu, G. Q., Xu, Q., et al. (2004). Neuron-specific apolipoprotein e4 proteolysis is associated with increased tau phosphorylation in brains of transgenic mice. J. Neurosci. 24, 2527-2534. doi: 10.1523/jneurosci.4315-03.2004

Brewer, G. J., Dick, R. D., Johnson, V. D., Brunberg, J. A., Kluin, K. J., Fink, J. K., et al. (1998). Treatment of Wilson's disease with zinc: XV long-term follow-up studies. J. Lab. Clin. Med. 132, 264-278. doi: 10.1016/s0022-2143(98) 90039-7

$\mathrm{Bu}, \mathrm{G}$. (2009). Apolipoprotein E and its receptors in Alzheimer's disease: pathways, pathogenesis and therapy. Nat. Rev. Neurosci. 10, 333-344. doi: 10.1038/ $\operatorname{nrn} 2620$

Bush, A. I., and Tanzi, R. E. (2008). Therapeutics for Alzheimer's disease based on the metal hypothesis. Neurotherapeutics 5, 421-432. doi: 10.1016/j.nurt.2008. 05.001

Caselli, R. J., Reiman, E. M., Locke, D. E., Hutton, M. L., Hentz, J. G., HoffmanSnyder, C., et al. (2007). Cognitive domain decline in healthy apolipoprotein E epsilon4 homozygotes before the diagnosis of mild cognitive impairment. Arch. Neurol. 64, 1306-1311. doi: 10.1001/archneur.64.9.1306

Caselli, R. J., Reiman, E. M., Osborne, D., Hentz, J. G., Baxter, L. C., Hernandez, J. L., et al. (2004). Longitudinal changes in cognition and behavior in asymptomatic carriers of the APOE e4 allele. Neurology 62, 1990-1995. doi: 10 1212/01.wnl.0000129533.26544.bf

Castellano, J. M., Kim, J., Stewart, F. R., Jiang, H., DeMattos, R. B., Patterson, B. W., et al. (2011). Human apoE isoforms differentially regulate brain amyloidbeta peptide clearance. Sci. Transl. Med. 3:89ra57. doi: 10.1126/scitranslmed. 3002156

Chen, J., Li, Q., and Wang, J. (2011). Topology of human apolipoprotein E3 uniquely regulates its diverse biological functions. Proc. Natl. Acad. Sci. U S A 108, 14813-14818. doi: 10.1073/pnas.1106420108

Corder, E. H., Saunders, A. M., Risch, N. J., Strittmatter, W. J., Schmechel, D. E., Gaskell, P. C. Jr., et al. (1994). Protective effect of apolipoprotein E type 2 allele for late onset Alzheimer disease. Nat. Genet. 7, 180-184. doi: 10.1038/ ng0694-180

Corder, E. H., Saunders, A. M., Strittmatter, W. J., Schmechel, D. E., Gaskell, P. C., Small, G. W., et al. (1993). Gene dose of apolipoprotein E type 4 allele and the risk of Alzheimer's disease in late onset families. Science 261, 921-923. doi: 10. $1126 /$ science. 8346443

Cui, L., Schoene, N. W., Zhu, L., Fanzo, J. C., Alshatwi, A., and Lei, K. Y. (2002). Zinc depletion reduced Egr-1 and HNF-3beta expression and apolipoprotein AI promoter activity in Hep G2 cells. Am. J. Physiol. Cell Physiol. 283, C623-C630. doi: 10.1152/ajpcell.00308.2001

Deane, R., and Zlokovic, B. V. (2007). Role of the blood-brain barrier in the pathogenesis of Alzheimer's disease. Curr. Alzheimer Res. 4, 191-197. doi: 10. 2174/156720507780362245

Duce, J. A., and Bush, A. I. (2010). Biological metals and Alzheimer's disease: implications for therapeutics and diagnostics. Prog. Neurobiol. 92, 1-18. doi: 10. 1016/j.pneurobio.2010.04.003

Dumanis, S. B., DiBattista, A. M., Miessau, M., Moussa, C. E., and Rebeck, G. W. (2013). APOE genotype affects the pre-synaptic compartment of glutamatergic nerve terminals. J. Neurochem. 124, 4-14. doi: 10.1111/j.1471-4159.2012. 07908.x

Fagan, A. M., Watson, M., Parsadanian, M., Bales, K. R., Paul, S. M., and Holtzman, D. M. (2002). Human and murine ApoE markedly alters A beta metabolism before and after plaque formation in a mouse model of Alzheimer's disease. Neurobiol. Dis. 9, 305-318. doi: 10.1006/nbdi.2002.0483

Fagan, A. M., Younkin, L. H., Morris, J. C., Fryer, J. D., Cole, T. G., Younkin, S. G., et al. (2000). Differences in the Abeta40/Abeta42 ratio associated with cerebrospinal fluid lipoproteins as a function of apolipoprotein E genotype. Ann. Neurol. 48, 201-210. doi: 10.1002/1531-8249(200008)48:2<201::aid-ana10>3. 3.co; 2 -o

Frieden, C., and Garai, K. (2012). Structural differences between apoE3 and apoE4 may be useful in developing therapeutic agents for Alzheimer's disease. Proc. Natl. Acad. Sci. U S A 109, 8913-8918. doi: 10.1073/pnas.1207022109

Fryer, J. D., Demattos, R. B., McCormick, L. M., O’Dell, M. A., Spinner, M. L., Bales, K. R., et al. (2005a). The low density lipoprotein receptor regulates the level of central nervous system human and murine apolipoprotein E but does not modify amyloid plaque pathology in PDAPP mice. J. Biol. Chem. 280, 25754 25759. doi: 10.1074/jbc.m502143200

Fryer, J. D., Simmons, K., Parsadanian, M., Bales, K. R., Paul, S. M., Sullivan, P. M., et al. (2005b). Human apolipoprotein E4 alters the amyloid-beta 40,42 ratio and promotes the formation of cerebral amyloid angiopathy in an amyloid precursor protein transgenic model. J. Neurosci. 25, 2803-2810. doi: 10.1523/jneurosci. 5170-04.2005

Grasso, G., Giuffrida, M. L., and Rizzarelli, E. (2012). Metallostasis and amyloid beta-degrading enzymes. Metallomics 4, 937-949. doi: 10.1039/c2mt20105d 
Greenough, M. A., Camakaris, J., and Bush, A. I. (2013). Metal dyshomeostasis and oxidative stress in Alzheimer's disease. Neurochem. Int. 62, 540-555. doi: 10. 1016/j.neuint.2012.08.014

Guo, C., Wang, P., Zhong, M. L., Wang, T., Huang, X. S., Li, J. Y., et al. (2013). Deferoxamine inhibits iron induced hippocampal tau phosphorylation in the Alzheimer transgenic mouse brain. Neurochem. Int. 62, 165-172. doi: 10.1016/j. neuint.2012.12.005

Gupta, V. B., Laws, S. M., Villemagne, V. L., Ames, D., Bush, A. I., Ellis, K. A., et al. (2011). Plasma apolipoprotein E and Alzheimer disease risk: the AIBL study of aging. Neurology 76, 1091-1098. doi: 10.1212/WNL.0b013e318211c352

Hara, M., Matsushima, T., Satoh, H., Iso-o, N., Noto, H., Togo, M., et al. (2003). Isoform-dependent cholesterol efflux from macrophages by apolipoprotein $\mathrm{E}$ is modulated by cell surface proteoglycans. Arterioscler. Thromb. Vasc. Biol. 23, 269-274. doi: 10.1161/01.atv.0000054199.78458.4b

Harris, F. M., Brecht, W. J., Xu, Q., Mahley, R. W., and Huang, Y. (2004). Increased tau phosphorylation in apolipoprotein E4 transgenic mice is associated with activation of extracellular signal-regulated kinase: modulation by zinc. J. Biol. Chem. 279, 44795-44801. doi: 10.1074/jbc.m408127200

Harris, F. M., Brecht, W. J., Xu, Q., Tesseur, I., Kekonius, L., Wyss-Coray, T., et al. (2003). Carboxyl-terminal-truncated apolipoprotein E4 causes Alzheimer's disease-like neurodegeneration and behavioral deficits in transgenic mice. Proc. Natl. Acad. Sci. U S A 100, 10966-10971. doi: 10.1073/pnas. 1434398100

Hatters, D. M., Zhong, N., Rutenber, E., and Weisgraber, K. H. (2006). Aminoterminal domain stability mediates apolipoprotein E aggregation into neurotoxic fibrils. J. Mol. Biol. 361, 932-944. doi: 10.1016/j.jmb.2006.06.080

Hirsch-Reinshagen, V., Zhou, S., Burgess, B. L., Bernier, L., McIsaac, S. A., Chan, J. Y., et al. (2004). Deficiency of ABCA1 impairs apolipoprotein E metabolism in brain. J. Biol. Chem. 279, 41197-41207. doi: 10.1074/jbc.m407962200

Hoke, D. E., Tan, J. L., Ilaya, N. T., Culvenor, J. G., Smith, S. J., White, A. R., et al. (2005). In vitro gamma-secretase cleavage of the Alzheimer's amyloid precursor protein correlates to a subset of presenilin complexes and is inhibited by zinc. FEBS J. 272, 5544-5557. doi: 10.1111/j.1742-4658.2005.04950.x

Holtzman, D. M., Herz, J., and Bu, G. (2012). Apolipoprotein E and apolipoprotein E receptors: normal biology and roles in Alzheimer disease. Cold Spring Harb. Perspect. Med. 2:a006312. doi: 10.1101/cshperspect.a006312

Hozumi, I., Hasegawa, T., Honda, A., Ozawa, K., Hayashi, Y., Hashimoto, K., et al. (2011). Patterns of levels of biological metals in CSF differ among neurodegenerative diseases. J. Neurol. Sci. 303, 95-99. doi: 10.1016/j.jns.2011. 01.003

Huang, Y., Liu, X. Q., Wyss-Coray, T., Brecht, W. J., Sanan, D. A., and Mahley, R. W. (2001). Apolipoprotein E fragments present in Alzheimer's disease brains induce neurofibrillary tangle-like intracellular inclusions in neurons. Proc. Natl. Acad. Sci. U S A 98, 8838-8843. doi: 10.1073/pnas.151254698

Hung, Y. H., Bush, A. I., and Cherny, R. A. (2010). Copper in the brain and Alzheimer's disease. J. Biol. Inorg. Chem. 15, 61-76. doi: 10.1007/s00775-0090600-y

Hung, Y. H., Bush, A. I., and La Fontaine, S. (2013). Links between copper and cholesterol in Alzheimer's disease. Front. Physiol. 4:111. doi: 10.3389/fphys.2013. 00111

Iqbal, K., Liu, F., Gong, C. X., and Grundke-Iqbal, I. (2010). Tau in Alzheimer disease and related tauopathies. Curr. Alzheimer Res. 7, 656-664. doi: 10. 2174/156720510793611592

Jones, N. (2010). Alzheimer disease: plasma clusterin predicts degree of pathogenesis in AD. Nat. Rev. Neurol. 6, 469. doi: 10.1038/nrneurol.2010.122

Jones, P. B., Adams, K. W., Rozkalne, A., Spires-Jones, T. L., Hshieh, T. T., Hashimoto, T., et al. (2011). Apolipoprotein E: isoform specific differences in tertiary structure and interaction with amyloid-beta in human Alzheimer brain. PLoS One 6:e14586. doi: 10.1371/journal.pone.0014586

Karlin, S., and Zhu, Z. Y. (1997). Classification of mononuclear zinc metal sites in protein structures. Proc. Natl. Acad. Sci. U S A 94, 14231-14236. doi: 10. 1073/pnas.94.26.14231

Kim, J., Basak, J. M., and Holtzman, D. M. (2009). The role of apolipoprotein E in Alzheimer's disease. Neuron 63, 287-303. doi: 10.1016/j.neuron.2009.06.026

Kitazawa, M., Cheng, D., and Laferla, F. M. (2009). Chronic copper exposure exacerbates both amyloid and tau pathology and selectively dysregulates cdk5 in a mouse model of AD. J. Neurochem. 108, 1550-1560. doi: 10.1111/j.1471-4159. 2009.05901.x

Kok, E., Haikonen, S., Luoto, T., Huhtala, H., Goebeler, S., Haapasalo, H., et al. (2009). Apolipoprotein E-dependent accumulation of Alzheimer disease-related lesions begins in middle age. Ann. Neurol. 65, 650-657. doi: 10.1002/ana. 21696

Lammich, S., Kojro, E., Postina, R., Gilbert, S., Pfeiffer, R., Jasionowski, M., et al. (1999). Constitutive and regulated alpha-secretase cleavage of Alzheimer's amyloid precursor protein by a disintegrin metalloprotease. Proc. Natl. Acad. Sci. U S A 96, 3922-3927. doi: 10.1073/pnas.96.7.3922

Lee, J. Y., Cho, E., Kim, T. Y., Kim, D. K., Palmiter, R. D., Volitakis, I., et al. (2010). Apolipoprotein E ablation decreases synaptic vesicular zinc in the brain. Biometals 23, 1085-1095. doi: 10.1007/s10534-010-9354-9

Lei, P., Ayton, S., Bush, A. I., and Adlard, P. A. (2011). GSK-3 in neurodegenerative diseases. Int. J. Alzheimers Dis. 2011:189246. doi: 10.4061/2011/189246

Linkous, D. H., Flinn, J. M., Koh, J. Y., Lanzirotti, A., Bertsch, P. M., Jones, B. F., et al. (2008). Evidence that the ZNT3 protein controls the total amount of elemental zinc in synaptic vesicles. J. Histochem. Cytochem. 56, 3-6. doi: 10. 1369/jhc.6a7035.2007

Liu, Q., Trotter, J., Zhang, J., Peters, M. M., Cheng, H., Bao, J., et al. (2010). Neuronal LRP1 knockout in adult mice leads to impaired brain lipid metabolism and progressive, age-dependent synapse loss and neurodegeneration. J. Neurosci. 30, 17068-17078. doi: 10.1523/JNEUROSCI.4067-10.2010

Liu, Q., Zerbinatti, C. V., Zhang, J., Hoe, H. S., Wang, B., Cole, S. L., et al. (2007). Amyloid precursor protein regulates brain apolipoprotein $\mathrm{E}$ and cholesterol metabolism through lipoprotein receptor LRP1. Neuron 56, 66-78. doi: 10. 1016/j.neuron.2007.08.008

Lovell, M. A., Robertson, J. D., Teesdale, W. J., Campbell, J. L., and Markesbery, W. R. (1998). Copper, iron and zinc in Alzheimer's disease senile plaques. J. Neurol. Sci. 158, 47-52. doi: 10.1016/s0022-510x(98)00092-6

Mahley, R. W., and Huang, Y. (2006). Apolipoprotein (apo) E4 and Alzheimer's disease: unique conformational and biophysical properties of apoE4 can modulate neuropathology. Acta Neurol. Scand. Suppl. 185, 8-14. doi: 10.1111/j.1600-0404. 2006.00679.x

Mahley, R. W., Rall, S. C., Jr. (2000). Apolipoprotein E: far more than a lipid transport protein. Annu. Rev. Genomics Hum. Genet. 1, 507-537. doi: 10.1146/ annurev.genom.1.1.507

Martic, S., Rains, M. K., and Kraatz, H. B. (2013). Probing copper/tau protein interactions electrochemically. Anal. Biochem. 442, 130-137. doi: 10.1016/j.ab. 2013.07.015

Mauch, D. H., Nagler, K., Schumacher, S., Goritz, C., Muller, E. C., Otto, A., et al. (2001). CNS synaptogenesis promoted by glia-derived cholesterol. Science 294, 1354-1357. doi: 10.1126/science.294.5545.1354

Michikawa, M., Fan, Q. W., Isobe, I., and Yanagisawa, K. (2000). Apolipoprotein E exhibits isoform-specific promotion of lipid efflux from astrocytes and neurons in culture. J. Neurochem. 74, 1008-1016. doi: 10.1046/j.1471-4159.2000. 0741008.x

Miyata, M., and Smith, J. D. (1996). Apolipoprotein E allele-specific antioxidant activity and effects on cytotoxicity by oxidative insults and beta-amyloid peptides. Nat. Genet. 14, 55-61. doi: 10.1038/ng0996-55

Moir, R. D., Atwood, C. S., Romano, D. M., Laurans, M. H., Huang, X., Bush, A. I., et al. (1999). Differential effects of apolipoprotein $\mathrm{E}$ isoforms on metal-induced aggregation of A beta using physiological concentrations. Biochemistry 38, 45954603. doi: 10.1021/bi982437d

Morante, S. (2008). The role of metals in beta-amyloid peptide aggregation: XRay spectroscopy and numerical simulations. Curr. Alzheimer Res. 5, 508-524. doi: 10.2174/156720508786898505

Morris, M., Maeda, S., Vossel, K., and Mucke, L. (2011). The many faces of tau. Neuron 70, 410-426. doi: 10.1016/j.neuron.2011.04.009

Morris, J. C., Roe, C. M., Xiong, C., Fagan, A. M., Goate, A. M., Holtzman, D. M., et al. (2010). APOE predicts amyloid-beta but not tau Alzheimer pathology in cognitively normal aging. Ann. Neurol. 67, 122-131. doi: 10.1002/ana.21843

Morrow, J. A., Hatters, D. M., Lu, B., Hochtl, P., Oberg, K. A., Rupp, B., et al. (2002). Apolipoprotein E4 forms a molten globule. A potential basis for its association with disease. J. Biol. Chem. 277, 50380-50385. doi: 10.1074/jbc.m204898200

Mulder, M., Jansen, P. J., Janssen, B. J., van de Berg, W. D., van der Boom, H., Havekes, L. M., et al. (2004). Low-density lipoprotein receptor-knockout mice display impaired spatial memory associated with a decreased synaptic density in the hippocampus. Neurobiol. Dis. 16, 212-219. doi: 10.1016/j.nbd.2004.01.015

Namba, Y., Tomonaga, M., Kawasaki, H., Otomo, E., and Ikeda, K. (1991). Apolipoprotein E immunoreactivity in cerebral amyloid deposits and neurofibrillary tangles in Alzheimer's disease and kuru plaque amyloid in CreutzfeldtJakob disease. Brain Res. 541, 163-166. doi: 10.1016/0006-8993(91)91092-f 
Narayanaswami, V., Maiorano, J. N., Dhanasekaran, P., Ryan, R. O., Phillips, M. C., Lund-Katz, S., et al. (2004). Helix orientation of the functional domains in apolipoprotein e in discoidal high density lipoprotein particles. J. Biol. Chem. 279, 14273-14279. doi: 10.1074/jbc.m313318200

Noda, Y., Asada, M., Kubota, M., Maesako, M., Watanabe, K., Uemura, M., et al. (2013). Copper enhances APP dimerization and promotes Abeta production. Neurosci. Lett. 547, 10-15. doi: 10.1016/j.neulet.2013.04.057

Pa, J., Boxer, A., Chao, L. L., Gazzaley, A., Freeman, K., Kramer, J., et al. (2009). Clinical-neuroimaging characteristics of dysexecutive mild cognitive impairment. Ann. Neurol. 65, 414-423. doi: 10.1002/ana.21591

Pan, E., Zhang, X. A., Huang, Z., Krezel, A., Zhao, M., Tinberg, C. E., et al. (2011). Vesicular zinc promotes presynaptic and inhibits postsynaptic long-term potentiation of mossy fiber-CA3 synapse. Neuron 71, 1116-1126. doi: 10.1016/j. neuron.2011.07.019

Paoletti, P., Vergnano, A. M., Barbour, B., and Casado, M. (2009). Zinc at glutamatergic synapses. Neuroscience 158, 126-136. doi: 10.1016/j.neuroscience.2008. 01.061

Pfrieger, F. W. (2003). Cholesterol homeostasis and function in neurons of the central nervous system. Cell. Mol. Life Sci. 60, 1158-1171.

Reaves, S. K., Wu, J. Y., Wu, Y., Fanzo, J. C., Wang, Y. R., Lei, P. P., et al. (2000). Regulation of intestinal apolipoprotein B mRNA editing levels by a zincdeficient diet and cDNA cloning of editing protein in hamsters. J. Nutr. 130, 2166-2173.

Rebeck, G. W., Reiter, J. S., Strickland, D. K., and Hyman, B. T. (1993). Apolipoprotein $\mathrm{E}$ in sporadic Alzheimer's disease: allelic variation and receptor interactions. Neuron 11, 575-580. doi: 10.1016/0896-6273(93)90070-8

Riddell, D. R., Zhou, H., Atchison, K., Warwick, H. K., Atkinson, P. J., Jefferson, J., et al. (2008). Impact of apolipoprotein E (ApoE) polymorphism on brain ApoE levels. J. Neurosci. 28, 11445-11453. doi: 10.1523/JNEUROSCI.1972-08.2008

Rosenblum, W. I. (2014). Why Alzheimer trials fail: removing soluble oligomeric beta amyloid is essential, inconsistent and difficult. Neurobiol. Aging 35, 969974. doi: 10.1016/j.neurobiolaging.2013.10.085

Sayre, L. M., Perry, G., Harris, P. L., Liu, Y., Schubert, K. A., and Smith, M. A. (2000). In situ oxidative catalysis by neurofibrillary tangles and senile plaques in Alzheimer's disease: a central role for bound transition metals. J. Neurochem. 74, 270-279. doi: 10.1046/j.1471-4159.2000.0740270.x

Smith, G. E., Bohac, D. L., Waring, S. C., Kokmen, E., Tangalos, E. G., Ivnik, R. J., et al. (1998). Apolipoprotein E genotype influences cognitive 'phenotype' in patients with Alzheimer's disease but not in healthy control subjects. Neurology 50, 355-362. doi: 10.1212/wnl.50.2.355

Spoerri, L., Vella, L. J., Pham, C. L., Barnham, K. J., and Cappai, R. (2012). The amyloid precursor protein copper binding domain histidine residues 149 and 151 mediate APP stability and metabolism. J. Biol. Chem. 287, 26840-26853. doi: 10.1074 /jbc.m112.355743

Squitti, R., Barbati, G., Rossi, L., Ventriglia, M., Dal Forno, G., Cesaretti, S., et al. (2006). Excess of nonceruloplasmin serum copper in AD correlates with MMSE, CSF [beta]-amyloid and h-tau. Neurology 67, 76-82. doi: 10.1212/01. wnl.0000223343.82809.cf

Squitti, R., Bressi, F., Pasqualetti, P., Bonomini, C., Ghidoni, R., Binetti, G., et al. (2009). Longitudinal prognostic value of serum "free" copper in patients with Alzheimer disease. Neurology 72, 50-55. doi: 10.1212/01.wnl.0000338568. $28960.3 \mathrm{f}$

Squitti, R., Simonelli, I., Ventriglia, M., Siotto, M., Pasqualetti, P., Rembach, A., et al. (2014). Meta-analysis of serum non-ceruloplasmin copper in Alzheimer's disease. J. Alzheimers Dis. 38, 809-822. doi: 10.3233/JAD-131247

Strittmatter, W. J., Weisgraber, K. H., Goedert, M., Saunders, A. M., Huang, D., Corder, E. H., et al. (1994). Hypothesis: microtubule instability and paired helical filament formation in the Alzheimer disease brain are related to apolipoprotein E genotype. Exp. Neurol. 125, 163-171; discussion 172-164. doi: 10.1006/exnr.1994.1019

Tokuda, T., Calero, M., Matsubara, E., Vidal, R., Kumar, A., Permanne, B., et al. (2000). Lipidation of apolipoprotein E influences its isoform-specific interaction with Alzheimer's amyloid beta peptides. Biochem. J. 348(Pt. 2), 359-365. doi: 10.1042/0264-6021:3480359

Tõugu, V., Karafin, A., Zovo, K., Chung, R. S., Howells, C., West, A. K., et al. (2009). $\mathrm{Zn}(\mathrm{II})$ - and $\mathrm{Cu}(\mathrm{II})$-induced non-fibrillar aggregates of amyloid-beta (1-42) peptide are transformed to amyloid fibrils, both spontaneously and under the influence of metal chelators. J. Neurochem. 110, 1784-1795. doi: 10.1111/j.14714159.2009.06269.x

Trougakos, I. P., Pawelec, G., Tzavelas, C., Ntouroupi, T., and Gonos, E. S. (2006). Clusterin/Apolipoprotein J up-regulation after zinc exposure, replicative senescence or differentiation of human haematopoietic cells. Biogerontology 7, 375382. doi: 10.1007/s10522-006-9052-8

Verghese, P. B., Castellano, J. M., and Holtzman, D. M. (2011). Apolipoprotein E in Alzheimer's disease and other neurological disorders. Lancet Neurol. 10, 241252. doi: 10.1016/s1474-4422(10)70325-2

Vural, H., Demirin, H., Kara, Y., Eren, I., and Delibas, N. (2010). Alterations of plasma magnesium, copper, zinc, iron and selenium concentrations and some related erythrocyte antioxidant enzyme activities in patients with Alzheimer's disease. J. Trace Elem. Med. Biol. 24, 169-173. doi: 10.1016/j.jtemb.2010. 02.002

Wahrle, S. E., Jiang, H., Parsadanian, M., Kim, J., Li, A., Knoten, A., et al. (2008). Overexpression of ABCA1 reduces amyloid deposition in the PDAPP mouse model of Alzheimer disease. J. Clin. Invest. 118, 671-682. doi: 10.1172/jci33622

Wahrle, S. E., Jiang, H., Parsadanian, M., Legleiter, J., Han, X., Fryer, J. D., et al. (2004). ABCA1 is required for normal central nervous system ApoE levels and for lipidation of astrocyte-secreted apoE. J. Biol. Chem. 279, 40987-40993. doi: 10.1074/jbc.m407963200

Wang, C., Vernon, R., Lange, O., Tyka, M., and Baker, D. (2010). Prediction of structures of zinc-binding proteins through explicit modeling of metal coordination geometry. Protein Sci. 19, 494-506. doi: 10.1002/pro.327

Wärmländer, S., Tiiman, A., Abelein, A., Luo, J., Jarvet, J., Söderberg, K. L., et al. (2013). Biophysical studies of the amyloid beta-peptide: interactions with metal ions and small molecules. Chembiochem 14, 1692-1704. doi: 10.1002/cbic. 201300262

Weisgraber, K. H., Roses, A. D., and Strittmatter, W. J. (1994). The role of apolipoprotein E in the nervous system. Curr. Opin. Lipidol. 5, 110-116. doi: 10. 1097/00041433-199404000-00007

White, A. R., Reyes, R., Mercer, J. F., Camakaris, J., Zheng, H., Bush, A. I., et al. (1999). Copper levels are increased in the cerebral cortex and liver of APP and APLP2 knockout mice. Brain Res. 842, 439-444. doi: 10.1016/s00068993(99)01861-2

Wildsmith, K. R., Holley, M., Savage, J. C., Skerrett, R., and Landreth, G. E. (2013). Evidence for impaired amyloid beta clearance in Alzheimer's disease. Alzheimers Res. Ther. 5, 33. doi: 10.1186/alzrt187

Xiong, Y., Jing, X. P., Zhou, X. W., Wang, X. L., Yang, Y., Sun, X. Y., et al. (2013). Zinc induces protein phosphatase $2 \mathrm{~A}$ inactivation and tau hyperphosphorylation through Src dependent PP2A (tyrosine 307) phosphorylation. Neurobiol. Aging 34, 745-756. doi: 10.1016/j.neurobiolaging.2012.07.003

Zhang, J. J., Wang, Y., and Lei, K. Y. (1995). Apolipoprotein A-I synthesis and secretion are increased in Hep G2 cells depleted of copper by cupruretic tetramine. J. Nutr. 125, 172-182.

Zhong, N., and Weisgraber, K. H. (2009). Understanding the association of apolipoprotein E4 with Alzheimer disease: clues from its structure. J. Biol. Chem. 284, 6027-6031. doi: 10.1074/jbc.r800009200

Zhou, L. X., Du, J. T., Zeng, Z. Y., Wu, W. H., Zhao, Y. F., Kanazawa, K., et al. (2007). Copper (II) modulates in vitro aggregation of a tau peptide. Peptides 28, 22292234. doi: 10.1016/j.peptides.2007.08.022

Conflict of Interest Statement: The authors declare that the research was conducted in the absence of any commercial or financial relationships that could be construed as a potential conflict of interest.

Received: 07 February 2014; accepted: 27 May 2014; published online: 12 June 2014. Citation: Xu H, Finkelstein DI and Adlard PA (2014) Interactions of metals and Apolipoprotein E in Alzheimer's disease. Front. Aging Neurosci. 6:121. doi: 10.3389/ fnagi.2014.00121

This article was submitted to the journal Frontiers in Aging Neuroscience.

Copyright $\odot 2014 \mathrm{Xu}$, Finkelstein and Adlard. This is an open-access article distributed under the terms of the Creative Commons Attribution License (CC BY). The use, distribution or reproduction in other forums is permitted, provided the original author(s) or licensor are credited and that the original publication in this journal is cited, in accordance with accepted academic practice. No use, distribution or reproduction is permitted which does not comply with these terms. 